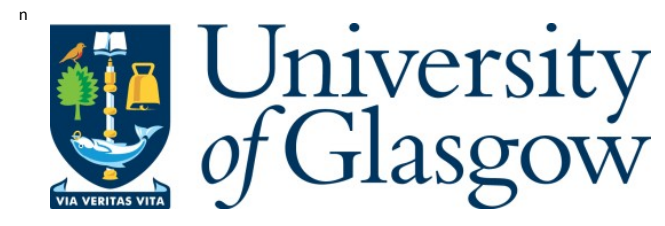

Davison, L., and Curl, A . (2014) A transport and health geography perspective on walking and cycling. Journal of Transport and Health, 1 (4). pp. 341-345. ISSN 2214-1405.

Copyright @ 2014 Elsevier Ltd.

A copy can be downloaded for personal non-commercial research or study, without prior permission or charge

Content must not be changed in any way or reproduced in any format or medium without the formal permission of the copyright holder(s)

http://eprints.gla.ac.uk/96705/

Deposited on: 05 N ovember 2014

Enlighten - Research publications by members of the University of Glasgow http://eprints.gla.ac.uk 


\title{
A Transport and Health Geography Perspective on Walking and Cycling
}

\section{Lisa Davison and Angela Curl}

\begin{abstract}
The impetus for this Viewpoint is to explore the ways in which health and transport geographers can add to understanding of the inter-relationship between health and nonmotorised travel, through interpretation of a conference session titled: 'Walking and Cycling - The contributions of health and transport geography' from the Royal Geographical Society (with the Institute of British Geographers) annual conference in 2013 convened by the authors, then to highlight where geographers can contribute theoretically, methodologically and practically.
\end{abstract}

\section{Background}

The motivation for this session, which was co-sponsored by Geographies of Health Research Group (GHRG) and the Transport Geography Research Group (TGRG), was to highlight to geographers the potential for the discipline to play a growing role in understanding the health benefits of non-motorised travel. We emphasise how research by geographers can complement the growing contributions of researchers from disciplines including public health and the built environment, particularly following the publication of the 'National Institute for Health and Care Excellence (NICE) public health guidance 41' (NICE, 2012) which called for more to be done to encourage walking and cycling, in recognition of the potential health benefits. The motivation for the viewpoint is to share details of the sessions with the wider research community - geographers and non-geographers. We would welcome a wider dialogue in response to this.

Questions we posed in our call for papers included: "Do people walk and cycle because of the perceived health benefits, because it is seen as sustainable and environmentally friendly or is it simply a necessity for some people, especially in the current economic climate?" Essentially we wanted to bring together geographers working in this field in order to establish the research being undertaken and create links as well as discussing how we can influence public policy and discuss more theoretically the role of geography. This expands on the work of Andrews et al. (2012) by emphasising the role of transport geographers as well as health geographers. As a whole, the session aims were aligned with those of the Journal of Transport and Health, which are to understand: "the many ways in which transport policy affects health and inequalities, how awareness of these links can affect transport policy 
decisions - and how poor health can affect transport options for individuals" (Mindell, 2014), in our case from a geographical perspective.

\section{Walking and Cycling: The contributions of health and transport geography}

The session sought to represent a range of methodological and critical viewpoints on walking and cycling. This resulted in what initially seemed an eclectic mix of presentations, which explored the contribution of geographers' research into active modes from theoretical through to applied and practical perspectives. From these it is clear that interaction between the health and transport geographers draws on a range of other disciplines to inform the theoretical and methodological approaches. Here we summarise the presentations in turn and reflect upon how they add to existing disciplinary and multidisciplinary knowledge and understanding.

Firstly, Davidson's 'A political ecology of the body in urban cycling', looked at the potential to apply new theoretical approaches to cycle commuting, drawing on a bodily approach (Davidson, 2013). Political ecology is a human geography approach to exploring complex relationships between nature and society (Gregory et al, 2009), applied here to the body it critiques environmental deterministic approaches to understanding cycling. Davidson's proposed $\mathrm{PhD}$ research uses this as a lens to explore urban cycling practices, arguing that this advances current research which examines the influence of individually held perceptions (e.g. Heinen, 2011) or capacities, cultural narratives (e.g. Aldred \& Jungnickel, 2014), or analyses of the built environment (e.g. Meng et al. 2014), or alternatively a combinations of these factors (e.g. Heesch et al. 2014). As an example of bodily approaches Davidson noted, that although political ecology has been applied in urban research on water (Swyngedouw et al., 2002), lawn care practices (Robbins et al., 2001) and obesity (Dodd, 2011) there has been less focus on transport, specifically cycling as noted by Creswell: "real bodies moving have never been at the top of the agenda in transport studies" (Creswell, 2010, p. 19). When presenting her work Davidson highlighted that research often concentrates on inanimate objects, such as social norms/habits/clothing/road conditions yet does not provide sufficient consideration of the relationship with the body. She explored the experiences of cycling, raising questions regarding the political and power dynamics of cycling for environmental reasons, knowledge which she intends to deepen through her postgraduate research. While the importance and valuable contribution of this research was discussed in the session, the challenges of influencing policy with theoretical work were recognised during positive dialogue between the author and civil servants at a preconference event at the Department for Transport (DfT). 
Davidson's perspective is part of a wider movement to further research based on bodily capabilities and inclinations. For instance, Andrews et al. (2012) argues that the disembodiment of walking has resulted in research which assumes a deterministic relationship between walkability, walking and health whereas other methodological approaches favoured by human geographers could deliver more critical approaches to understanding of walking.

This was followed by presentations from Lindelöw and Rind, who each looked at facets of "walkability". The extent to which the environment is conducive to walking is a growing area of study which Talen and Koschinsky (2013) call a 'crowded research landscape' and which Andrews et al. (2012) claim is 'one of the most popular focuses of 'non-medical' research today'. Andrews et al. also highlight that measuring such a concept is inherently geographical. Whilst research on walkability traditionally focuses on the built environment Lindelöw and Rind each adapted their approach to consider the influence of other factors. In contrast to the first paper they each take a more positivist approach; these are discussed in turn.

Lindelöw (2013) draws upon social ecological theories (Humpel et al. 2002), conceptualising the inter-relationships between an individual's walking behaviour and their environmental perceptions, highlighting that walking is a function of an individual's interaction with and perception of the environment, rather than simply environmentally determined. The theoretical and methodological underpinnings are based on the work of Alfonzo et al. (2005), which considers the feasibility of walking. For a more thorough examination of the results, please refer to Lindelöw et al. 2014 (this issue) but key points are that Lindelöw recognises the role that transport studies, urban studies and health sciences have had in shaping research on non-motorised travel so far and he uses this as a basis to argue that researchers must understand individual time/space influences upon the feasibility of walking for everyday activities. During the session he presented a compelling argument for more research into walking as a mode of transport, focussing on the process and not just outcomes related to crude measures of the built environment, concurring to an extent with the earlier presentation by Davidson. This links to work such as that of Talen and Koschinsky (2013), which questions the normative idea that a walkable environment is good for everyone, or indeed that the same attributes will make an environment walkable for all.

Rind (Rind et al., 2013) presented a paper as a step to '[integrate] environmental justice and socio-ecological models of health to understand population-level physical activity' Rind's presentation highlighted the applied approach: utilising multi-level models to examine how indices designed to measure aspects of the natural environment influenced active travel 
behaviours based on national travel survey data. Whilst the influence beyond the built environment was emphasised, the proposed environmental index held no clear relationship with active travel across the population segments under consideration. However, the paper presented a range of interesting hypotheses and was particularly effective in emphasising inequalities, noting specifically that active travel may not be health promoting amongst all social groups. Amore recent paper (Shortt et al., 2014) highlights this complexity further with the key findings being that individuals in less deprived areas were most likely to achieve recommended physical activity levels when compared to the most deprived both overall and with respect to walking for all purposes or recreational purposes. However, the reverse was true for non-recreational purposes with individuals in the most deprived areas benefitting most from utilitarian walking.

Whilst this presentation was theoretically grounded and supported by the wider literature, criticism of similar approaches include that many studies of the built environment, or in this case the natural environment, in relation to physical activity assume a deterministic role of the environment (Nelson et al. 2008). Further to this, researchers examining the role and effectiveness of such indices (Talen \& Koschinsky 2013) also highlight caution as to using a "one-size-fits-all" approach. This is countered by the argument that such an approach can also deliver a level of understanding and generalisability. From a pragmatic perspective, Rind's discussion of the inequalities links to Davidson's discussion as to who benefits from active travel and the need to explore the ways in which they benefit. Therefore, it could be argued that in conjunction these approaches can provide a more thorough understanding of active travel in relation to geography and health.

Lee (Lee, 2013a) and Johnson (Johnson \& Margolis, 2013a) each presented case studies evaluating practical interventions to encourage active travel. Lee focussed upon how Living Streets' community partnership approach to delivering environmental improvement, the Fitter for Walking project, encouraged walking, whilst Johnson evaluated the role of adult cycle training in promoting confidence in Tower Hamlets. Each emphasised the ability of simple and relatively cheap interventions to facilitate behavioural change, with Fitter for Walking claiming cost-benefit ratio of up to 46:1 (Lee, 2013a) and Tower Hamlets' adult cycle training achieving cost benefits close to 5:1 (Johnson \& Margolis, 2013b). Both studies had used the Health Economic Assessment Tool (HEAT) (Kahlmeier et al., 2011) to assess the economic cost-benefit of the schemes though they expanded upon this by using mixed method approaches which also considered the stakeholder's qualitative responses.

Lee (2013a) described the way Living Streets engaged with communities to involve them in 'creating streets for people' and encouraging them to make walking pledges. Community 
input steered the 'Fitter for Walking' projects which were delivered across range of geographical areas in England. This resulted in a range of environmental and promotional interventions, which based on surveying residents resulted in an increased amount of walking, community engagement and contact with neighbours. This shows the benefits of walking beyond physical activity which may have wider health impacts, for example related to loneliness and mental health, particularly in older age Further, given that Fitter for Walking was delivered as a package through community engagement (Lee, 2013b) highlight the importance of considering the process by which interventions are delivered, as this may impact on the outcomes which can be achieved. This can be evidenced from the qualitative analysis commending the process of community engagement and the inclusiveness of the outcomes (Adams et al. 2012).

Johnson (Johnson \& Margolis, 2013a) presented an evaluation of the outcomes of adult cycle training in Tower Hamlets. In reporting this, Johnson and Margolis (2013b) highlighted challenges in evaluating the impact of transport interventions introduced as a part of a 'package of measures'. Hence the authors applied a before and after methodology to evaluate the impact of a small scale intervention upon overall physical activity levels as well as mode choice. They found that participants responding to the before and after survey had increased their amount of cycling and overall physical activity, were more likely to own a bicycle and had increased confidence in their cycling ability. This evidences that for this intervention has impacted on mode choice and increased physical activity, delivering wider health benefits.

The last two presentations, by Lee and Johnson, focused more on established approaches to evaluation of practical interventions, applied across disciplines, not specifically geographical as such, but of interest to health and transport geographers. However, this emphasis added to the session as a whole. Furthermore, as a participant currently employed as a practitioner when presenting (though some other participants had also held more practical roles) Lee raised questions about how geographers can contribute to practitioner knowledge and evaluation practices. In a climate of competing for resources she emphasised the demand for evidence which can be used to prove the benefits of interventions such as that presented to enable organisations such as Living Streets to win funding to deliver further projects. This is an interesting consideration for both health and transport geographers involved in policy focussed research. These presentations highlighted the complementarity of mixed methods approaches, balancing the use of positivist, more rigid, matrix-based metrics to assess costs and benefits, with more nuanced understandings enabled through a more qualitative approach. 
The discussion that followed the session proved that despite the breadth in approach, in reality there was a strong link between each paper with themes such as community, health, the built environment, policy, politics and practice being emphasised throughout. It was recognised that the discourse of health enables walking and cycling research but can also be problematic. Many transport researchers do not adhere to the public health approach to measuring the built environment for physical activity, but as highlighted by Andrews et al. (2012) health (and transport) geographers can contribute to moving beyond such systematic measurement. Potential tensions between the aims of health and transport professionals in relation to active travel behaviours were also discussed with respect to making comparative evaluations. For instance, whilst the health focus is clearly on physical activity, from a transport perspective the motivation is more often sustainable transport and reduction of emissions (which would also have 'co-benefits' such as those related to health (Giles-Corti et al., 2010). In summary the presenters highlighted the range of ways in which transport and health geographers can contribute to understanding active travel (or non-motorised modes) and the inter-relationship with health, ranging from the theoretical to the practical.

\section{Developments in the geographical contribution to walking and cycling}

Much interest in the field of improving public health through physical activity, particularly walking and cycling, has focussed on measuring the built environment by identifying attributes which will be conducive to walking and cycling and thus lead to positive health outcomes. This has resulted in a plethora of research into "walkability" (Talen \& Koschinsky, 2013; Andrews et al., 2012). There have been recent calls by academics for planning and health to be brought back into closer contact (Koohsari et al., 2013; Rao et al., 2007), which implies a need to understand what kind of environment will lead to desirable health outcomes. Although geographers are well placed to understand the relationship between planning, the environment and travel behaviour, much recent interest comes from outside of geography, for example from built environmental and public health. Here we outline areas where we believe geographers can contribute to the field.

It cannot be assumed that simply by developing a "walkable" (or "cyclable") environment, public health goals will be achieved; the relationships are more complex than this (Andrews et al., 2012). As emphasised in a practical sense by Johnson and Margolis (20131a, 2013b) and Lee (2013a, 2013b) specific interventions can be as effective and these may or may not include changes to the physical environment. Focussing more on the theoretical and methodological the other presenters highlight a range of potential influences reaching beyond the built environment. As highlighted by Lindelöw there is a need to consider not just the objective but perceptions of the environment for walking (Inoue et al., 2010) and cycling 
(Ma et al., 2014). In addition to the built environment, social factors are likely to be important for walking and cycling behaviour and vary across space and time. Hence, studies should also consider perceptions (see for example, van Acker et al., 2010) of factors influencing walking and cycling, such as traffic, crime and road safety. Although an area may be deemed "walkable" or "cyclable", if it is not perceived as such, then health benefits achieved through physical activity are unlikely to be realised. Furthermore, such studies often fail to recognise the complexities of mode choice and individuals' motivations, perceptions and desires as well as the environment. In summary geographers should think critically about the socio-spatial environment and the relationship to health outcomes.

As highlighted by Rind et al. and Andrews et al. (2012), attention should be paid to inequality, both in the built environment in terms of its ability to facilitate walking and cycling as well as active travel behaviours, which may or may not be related to the environment. Inequalities in access to services have been extensively studied by geographers, often in a social justice context (e.g. Lucas, 2006), including mobilities and health (Gatrell, 2011); this can be extended to focus at a more micro level on the built environment (Shortt et al., 2014).

The laudable goals of improving public health through increased physical activity, which encompasses walking and cycling as an option for journeys where distance and mobility allows, should also be critiqued. As pointed out by Rind et al., active travel may not have health benefits among all social groups and for some encouraging physical activity through active travel may be at odds with other policy goals such as ensuring equality of access to services (by any mode) or simply unrealistic e.g. for elderly and mobility impaired, rural or low income groups. Goodman (2013) notes the already high levels of active travel among lower income groups, suggesting that in contrast to other health behaviours physical activity through active travel is more common among deprived communities. The mobility requirements and abilities of groups should therefore be considered. Mobilities researchers study mobility as range of practices, not just attributable to the environment or the individual but culturally and historically embedded, focussing on daily practices and routines. Related to this there is potential to study transport, travel, mobility and health across the life course.

Geographers can therefore contribute by thinking in a more nuanced way about individual limitations. Spatial planning means that car is often a necessity, and once bought it is likely to be used for more journeys as the marginal costs are low. There is therefore a need for a more strategic approach reducing car dependency at a societal and not just an individual level. Health and transport geographers may seek to address problems in different ways and with differing objectives, hence our focus on bringing researchers from these sub-disciplines together. In the simplest form a public health practitioner may focus on improving active 
travel as a means of physical activity through the use of individual health messages, a transport planner may seek to integrate land use in order to reduce car dependency resulting in a more efficient transport system. Transport and health geographers are well placed to understand issues and solutions at a variety of scales thus provide further understanding of the complexities in achieving multi-faceted objectives relating to walking and cycling. Our focus in this short piece has been on individual's physical activity outcomes achieved through active travel although there are many other areas where transport and health geographers might contribute to research into walking and cycling. For example, by focussing at different scales, geographers also research the relationships of transport and health through climate change, sustainable travel and air quality (Cohen et al., 2014) which also have population health impacts beyond physical activity. Similarly, there are other positive health outcomes such as mental health, social contact and quality of life and wellbeing, rather than physical activity which are strongly linked to discourses of obesity and heart related ill-health.

\section{Acknowledgements}

The authors would like to thank the Geographies of Health Research Group (GHRG) and the Transport Geography Research Group (TGRG) for sponsoring the 'Walking and Cycling The contributions of health and transport geography' session at the RGS-IBG conference 2013. They are particularly grateful for the presenters and other contributors who ensured the success of the session and ensuing discussions. They would also like to thank two anonymous reviewers for taking the time to share their thoughts on an earlier version of this Viewpoint.

\section{References}

Adams, E.J., Goad, M.A. and Cavill, N. (2012) Evaluation of Living Streets' Fitter for Walking Project. BHF National Centre for Physical Activity and Health. School of Sport Exercise and Health Sciences, Loughborough University, Loughborough, UK. Available at: http://www.livingstreets.org.uk/sites/default/files/content/library/Evaluations/FFW Evaluation Report FINAL 31Jan2012.pdf accessed 28/05/14

Aldred, R. and Jungnickel, K. (2014) Why culture matters for transport policy: the case of cycling in the UK, Journal of Transport Geography, 34:78-87, ISSN 0966-6923, http://dx.doi.org/10.1016/j.jtrangeo.2013.11.004. 
Alfonzo, M., Boarnet, M.G., Day, K., McMillan, T., and Anderson, C.L. (2008) The Relationship of Neighbourhood Built Environment Features and Adult Parents' Walking. Journal of Urban Design 13, 29-51.

Andrews, G., Hall, E., Evans, B., and Colls., R (2012) Moving beyond walkability: On the potential of health geography. Social Science and Medicine. 75(11):1925-32

Cohen, J., Boniface, S. and Watkins, S. (2014) Health implications of transport planning, development and operations. Journal of Transport and Health 1:63-72

Creswell, T. (2010) Towards a politics of mobility. Environment and Planning D: Society and Space. 28: 17-31.

Davidson, A. (2013) A political ecology of the body in urban cycling. Presentation at RGSIBG Annual International Conference. London

Dodd, Warren (2011) "Towards a Political Ecology of Nutritional Transitions in Central America: The Construction of Nutrient-Deficient Ecologies," Totem: The University of Western Ontario Journal of Anthropology: Vol. 19: Iss. 1, Article 10.

Giles-Corti, B., Foster, S., Shilton, T. and Falconer, R. (2010) The co-benefits for health of investing in active transportation. New South Wales public health bulletin 21(5-6):122-7.

Gatrell, A. (2011) Mobilities of Health, Farnham, Ashgate

Goodman, A. (2013) Walking, Cycling and Driving to Work in the English and Welsh 2011Census: Trends, Socio-Economic Patterning and Relevance to Travel Behaviour in General. PLOS ONE. 8(8):e71790

Gregory, D; Johnston, R; Pratt, G; Watts, MJ; Whatmore, S (2009) The Dictionary of Human Geography . John Wiley \& Sons, Ltd.

Heesch, K.C. Giles-Corti, B. and Turrell, G. (2014) Cycling for transport and recreation: Associations with socio-economic position, environmental perceptions, and psychological disposition, Preventive Medicine, 63: 29-35,

Heinen, E. Maat, K. and van Wee, B. (2011) The role of attitudes toward characteristics of bicycle commuting on the choice to cycle to work over various distances, Transportation Research Part D: Transport and Environment, 16(2): 102-109, 
Humpel, N., Owen, N. and Leslie, E. (2002) Environmental factors associated with adult's participation in physical activity. A review. American Journal of Preventive Medicine. 22:188199

Inoue, S., Ohys, Y., Odagiri, Y., Takamiya, T., Ishii, K., Kitabayashi, M., Suijo, K., Sallis, J.F. and Shimomitsu, T. (2010) Association between Perceived Neighbourhood Environment and Walking among Adults in 4 Cities in Japan. Journal of Epidemiology 20(4):277-286

Johnson, R. and Margolis, S. (2013a) Measuring Behavioural Change: An Evaluation of Adult Cycle Training in the London Borough of Tower Hamlets. Presentation at RGS-IBG Annual International Conference. London.

Johnson, R. and Margolis, S. (2013b) A review of the effectiveness of adult cycle training in Tower Hamlets, London. Transport Policy 30:254-261.

Kahlmeier, S., Cavill, N., Dinsdale, H., Rutter, H., Götschi, T., Foster, C., Kelly, P., Clarke, D., Oja, P., Fordham, R., Stone, D., Racioppi, F. (2011) Health economic assessment tools (HEAT) for walking and for cycling: Methodology and user guide, World Health Organization Europe. Available: www.heatwalkingcycling.org accessed 28/05/14

Koohsari, M.J., Badland, H. and Giles-Corti, B. (2013) (Re)Designing the built environment to support physical activity: Bringing public health back into urban design and planning.

Cities. 35:294-98

Lee, R (2013a) Fitter for Walking Project. Presentation at RGS-IBG Annual International Conference. London. Slides Available:http://www.slideshare.net/LisaDavison1/rgs-fitter-forwalking-pecha-kucha accessed 28/05/14

Lee, R. (2013b) Community led Interventions to promote Walking. Transportation Professional. CIHT.

Lindelöw, D. (2013) Walkability as Feasibility-studying walking in the built environment from a transport perspective. Presentation at RGS-IBG Annual International Conference. London.

Lindelöw, D., Svensson, A., Johansson, M. and Sternudd, C. (2014) Every-day walkability: Perceptions of walking in the built environment from a transport perspective. Journal of Transport and Health.

Lucas, K. (2006) Providing transport for social inclusion within a framework for environmental justice in the UK. Transportation Research Part A: Policy and Practice. 40(10):801-809 
Ma, L., Dill, J. and Mohr, C. (2014) The objective versus the perceived environment: what matters for bicycling? Transportation. Online First. 10.1007/s11116-014-9520-y

Meng, M. Koh, P.P. Wong, Y.D. and Zhong, Y.H. (2014) Influences of urban characteristics on cycling: Experiences of four cities, Sustainable Cities and Society, in press.

Mindell, J.S. (2014) Welcome to the Journal of Transport and Health. Journal of Transport and Health 1(1):1

Nelson, N.M., Wright, A., Lowry, R.G. and Mutrie, N. (2008) Where is the theoretical basis for understanding and measuring the environment for physical activity? Environmental Health Insights, 2:111-116.

National Institute for Health and Care Excellence (NICE) (2012) Walking and cycling: local measures to promote walking and cycling as forms of travel or recreation. NICE public health guidance 41. Available: http://www.nice.org.uk/nicemedia/live/13975/61629/61629.pdf accessed 28/05/14

Rao, M., Prasad, S., Adshead, F. and Tissera, H. (2007) The built environment and health. The Lancet 370:1111-1113

Rind, E., Shortt, N., Pearce, J. and Mitchell, M (2013) Does the natural environment impact travel behaviours?. Presentation at RGS-IBG Annual International Conference. London.

Robbins, P., Polderman, A. and Birkenholtz, T. (2001) Lawns and Toxins: An Ecology of the City. Cities 18(6):369-380

Shortt N.K., Rind E., Pearce J. and Mitchell R. (2014) Integrating environmental justice and socio-ecological models of health to understand population-level physical activity.

Environment and Planning $A$, in press

Swyngedouw, E. Kaïka, M.Castro, E. (2002) Water Management in Urban Areas, Built Environment 28(2):124-137

Talen, E. and Koschinsky, J (2013) The Walkable Neighborhood: A Literature Review. International Journal of Sustainable Land use and Urban Planning 1(1): 42-63.

Van Acker, V., van Wee, B and Witlox, F (2010) When transport geography meets social psychology: Toward a conceptual model of travel behaviour. Transport Reviews 30(2): 219240. 